\title{
GERAÇÕES EM CONFLITO NAS NARRATIVAS DE ETGAR KÉRET
}

\author{
CONFLICT GENERATIONS IN ETGAR KÉRET NARRATIVES
}

Gabriel Steinberg*

\begin{abstract}
Resumo: A sexta antologia de narrativas curtas Takalá Biktzê hagalaksia (Um incidente nos confins da Galáxia), rendeu ao escritor israelense Etgar Kéret o prêmio Sapir em 2018. Como é marca de sua escrita, suas narrativas se dirigem ao leitor numa linguagem coloquial e informal. Sua escrita por vezes bem humorada tem como personagens pessoas comuns, que em situações peculiares têm um comportamento extremo e até bizarro.
\end{abstract}

Palavras-chave: Etgar Kéret. Literatura israelense. Humor.

\begin{abstract}
The sixth anthology of short narratives Takalá Biktzê hagalaksia (An incident in the far reaches of the Galaxy), won the Israeli writer Etgar Kéret the Sapir prize in 2018. As a mark of his writing, his narratives are addressed to the reader in a colloquial and informal language. His sometimes humorous writing has as characters common people who, in peculiar situations, have an extreme and even bizarre behavior.
\end{abstract}

Keywords: Etgar Kéret. Israeli literature. Humor.

Para os escritores nascidos na Terra de Israel antes da independência e que se tornaram conhecidos como os integrantes da Geração da Guerra da Independência, ou a Geração da Terra, a ideologia sionista socialista exerceu forte influência sobre suas narrativas. Eles acreditavam nos valores coletivistas do Movimento Trabalhista. Para eles a função do jovem hebreu, que recebeu a denominação de sabra, era construir a pátria, defendê-la com sua própria vida e ligar seu destino ao destino de seus companheiros e de seu povo.

Os escritores do período que antecedeu à criação do Estado de Israel, em 1948, contribuíram com suas obras para propagar vários mitos sionistas. A maioria deles analisou o cotidiano israelense sob a ótica de sua identificação pessoal e sentimental como um "milagre" prestes a ocorrer. Em suas obras não havia críticas nem à empreitada sionista e nem aos indivíduos que se engajaram nessa empreitada. A literatura do período formativo do estado foi uma literatura que tentou mostrar uma sociedade coesa, justa, idealista, sem conflitos internos e sem disputas intergeracionais. Os únicos embates mostrados na literatura eram os da sociedade judaica lutando contra os árabes ou os britânicos. Os heróis das obras literárias da época eram sempre os combatentes sabras estereotipados: donos de um agir reto e direto, dispostos a sacrifícios ilimitados em prol de seu povo, sérios em suas concepções ideológicas e possuidores de uma fala curta e entrecortada por gírias. Seus sofrimentos e desejos refletiam o sofrimento e os desejos coletivos e nunca os pessoais ou íntimos. Na literatura da época, os jovens sabras sentiam um temor reverencial ante a figura dos pais fundadores da empreitada sionista e perante os pioneiros. Eles deviam mostrar uma identificação com o mundo de seus pais, com seus professores e com os líderes da nação. Os jovens tinham consciência de que não podiam decepcionar seus pais, ao contrário, eles deviam atender às expectativas destes em tudo o que se relacionava com os objetivos sionistas. Muitos jovens sentiam que a primeira geração no

\footnotetext{
* Gabriel Steinberg é professor no Departamento de Letras Orientais da Faculdade de Filosofia, Letras e Ciências Humanas da Universidade de São Paulo. E-mail: <steinberg1818@usp.br>.
} 
país os colocara à prova, e eles deviam, por isso, esforçar-se ao máximo não somente para não decepcioná-los, mas também para superá-los em coragem e altruísmo, mostrando permanentemente seu heroísmo e disposição para o sacrifício.

Os jovens nascidos no país alistavam-se voluntariamente para as missões militares mais perigosas. O jovem israelense devia mostrar-se socialmente como um soldado, de preferência como parte de uma comuna agrícola e como um membro partidário e ideológico notável. O exemplo, ao menos no discurso oficial, era o do jovem que desbravava novas terras e concretizava com seu suor o sonho sionista. O comentário de Amós Oz no romance De Amor e Trevas, ilustra o contraste entre a imagem criada em torno da figura do sabra no contexto agrícola com a geração de seus pais oriundos da Europa, mas também o desejo de $\mathrm{Oz}$ e o de outros jovens, que como ele nasceram na Terra de Israel pouco antes da independência, de serem diferentes de seus pais, nascidos na diáspora. A citação a seguir deixa claro o conflito intergeracional velado, o que obviamente contrariava o discurso oficial. Assim $\operatorname{diz} \mathrm{Oz}$

\begin{abstract}
No começo da década de 1950, o polo oposto à casa paterna era o kibuts. Lá, longe de Jerusalém, 'para além das montanhas das trevas', na Galiléia, no Sharon, no deserto do Nêguev e nos vales, florescia assim pensávamos na Jerusalém daquele tempo, uma nova raça, sólida, de pioneiras e pioneiros, sérios mas não complicados, de poucas palavras, que sabiam guardar segredos, capazes de dançar e rodopiar vertiginosamente até a embriaguez, mas também afeitos ao isolamento, à reflexão, e acostumados à vida no campo e às tendas dos acampamentos: rapazes e moças robustos, obstinados, prontos a realizar qualquer tipo de trabalho, mas mantendo uma vida espiritual rica, plena, de sentimentos profundos. Eu queria ser como eles para não ser como meu pai, nem como minha mãe, nem como os literatos refugiados melancólicos que enchiam a Jerusalém judia. ${ }^{1}$
\end{abstract}

Já a literatura dos anos 50 e 60 do século XX se mostra como a "literatura do desengano". Uma vez que os valores do coletivismo, ideologia que levou à criação do estado, ficaram abalados, era preciso encontrar valores individuais com os quais fosse possível prosseguir. $\mathrm{O}$ arquétipo do herói desapareceu gradualmente, era urgente encontrar a figura do anti-herói para representar a nova realidade social e literária. A nova geração de escritores, a chamada Geração do Estado, encarou Israel tanto com suas qualidades quanto com seus defeitos e fraquezas. A identidade dos israelenses nativos ou os que cresceram no país, refletiu-se e desenvolveu-se nas obras literárias de Amós Oz e A. B. Yeoshua, os principais representantes desta geração. Eles se tornaram os mais representativos, mas não os únicos porta-vozes da chamada "narrativa modernista sionista". Segundo Yigal Schwartz "a trama central das obras escritas pela Geração do Estado gira em torno das tensões não resolvidas entre individuo e sociedade, nação e Estado".2

Os protagonistas das narrativas dessa geração lutam para impedir que sua individualidade seja esmagada pela tirania da doutrina sionista baseada na exaltação do coletivo. O que caracterizou a literatura desse período segundo Rozenchan foram

As várias versões da narrativa modernista sionista baseadas em duas oposições, a intergeracional e a homem-mulher. O foco da narrativa situavase quase sempre no conflito entre pais e filhos e era essencialmente masculino. Como um conflito pai-filho nunca pode ser totalmente resolvido, não há

\footnotetext{
${ }^{1}$ OZ, 2005, p. 490.

${ }^{2}$ SCHWARTZ, 1998, p. 23.
} 
situações de preponderância total, mas somente interações breves, violentas e destrutivas. $^{3}$

No conto O Silêncio Contínuo de um Poeta, publicado por A.B. Yeoshua no final da década de 1960, encontramos uma mostra do conflito intergeracional tal como ele aparece na ótica dos escritores da Geração do Estado. O narrador do conto, um poeta esquecido e decadente já avançado em anos teve um filho o qual ele rejeita profundamente. Sobre esse nascimento ele diz: "É um mero acidente. Ao final de contas, ele não se parece comigo, e entre mim e ele só existe em comum um fino traço de agressividade". ${ }^{4}$ A seguir ele continua: "Ele é meu filho caçula. Nasceu incidentalmente, por engano, por uma espécie de milagre amaldiçoado, pois já estávamos ambos, a mãe dele e eu beirando a velhice". 5

O menino nasceu silenciosamente com uma lentidão imperceptível. Na narrativa ele é constantemente chamado pelo pai de "retardado". O menino é rejeitado pelo pai por ser diferente, desajeitado e isolado. Quando as irmãs do garoto faziam festas em casa, elas exigiam do pai que o escondesse, e o pai as atendia. Nem no casamento de uma das irmãs ele pode participar "só o trouxeram de volta altas horas da noite". ${ }^{6} \mathrm{O}$ pai o rejeita ao longo de toda a narrativa e não cansa de dizer: "E assim começou a nossa vida em comum, um junto do outro, numa casa sossegada... Eu um poeta que se calara, e ele - um menino retardado, solitário. Até na escola, os professores o consideravam como alguém que não pode ser recuperado".

O menino cresceu nas sombras como uma espécie de Golem, realizando os serviços domésticos, limpando a casa, descalçando os sapatos do pai, cuidando do jardim, cozinhando, mas no entanto sem emitir qualquer palavra. O silêncio reinava entre filho e pai e este apenas se questionava sobre o que ele poderia falar com esse menino?. No último ano escolar, três semanas antes do término das aulas, estudaram na sua classe um dos poemas de seu pai. Foi nesse momento que o rapaz não pode mais se conter, ele ficara emocionado com o fato. Quando o pai chegou em casa, o garoto se pôs a ler aquele poema. Foi o momento em que uma luz se acendeu no garoto, mas o pai não encontrou o caminho da comunicação com seu filho. Ao final do conto, o pai descobre atônito que seu filho escrevia a seu modo poesias e viu seu nome, com letras trêmulas delineado no alto do poema. O menino tentou encontrar por meio da poesia uma ligação com seu pai que, no entanto, o rejeita até o final.

A mesma linha narrativa e ideológica é seguida por Amós $\mathrm{Oz}$ no conto $O$ Caminho do Vento, publicado também na década de 1960, e que tem como ponto central o conflito intergeracional entre o pioneiro e líder sionista Shimshon Sheinboim e Guideon, seu filho desajeitado, magro e desengonçado que em nada corresponde ao modelo do sabra idealizado e desejado por seu pai. A trama se sucede no dia da independência de Israel, ocasião na qual um grupo de paraquedistas pulará do céu sobre o kibuts Nof Harish, e entre eles se encontra Guideon que terá mediante esse ato, a oportunidade de se redimir aos olhos dos moradores do lugar, mas principalmente, aos olhos de seu pai, um conhecido herói nacional, um dos pioneiros da empreitada sionista.

Já no início do conto Guideon é uma humilhação para Shimshon, considerado um grande herói de Israel e sobre o qual o narrador nos conta:

Ele não permitia que sua posição de principal ideólogo do movimento o dispensasse dos deveres de qualquer membro do kibuts: guarda noturno, plantações, mutirão no período da colheita. Nenhuma sombra de falsidade tolda a vida de Shimshon Sheinboim desde sempre e até hoje. Ele é um bloco

\footnotetext{
${ }^{3}$ ROZENCHAN, 2008, p. 131.

${ }^{4}$ YEOSHUA, 1978, p. 138.

5 YEOSHUA, 1978, p. 138.

${ }^{6}$ YEOSHUA, 1978, p. 143.
} 
compacto de ideais e realizações que desconhece esmorecimentos ou hesitações. $^{7}$

Diante da grandeza do pai, Guideon é o oposto e por isso causa desconforto a Shimshon. Ele é descrito pelo narrador tal como é visto pelo pai: "um jovem moreno, tenro, de uma beleza quase feminina, cortando sempre os caminhos do kibuts num silêncio obstinado. Não se destaca no trabalho. Não se destaca na vida social. Fala lentamente e, com certeza também pensa lentamente". 8

No último dia de vida de Guideon ele conseguiu constranger seu pai mais uma vez e de forma arrasadora. Ao pular de paraquedas sobre o kibuts, desobedecendo as ordens de seu comandante e com o intuito de ser visto e percebido por todos, Guideon abriu o primeiro paraquedas e a seguir o segundo, que somente poderia ser aberto em caso de emergência, e com isso acabou sendo levado pelo vento para longe, pousando sobre um cabo de alta tensão. Após inúmeras tentativas de salvamento e súplicas do pai para que pulasse e assim salvasse sua vida, e após ouvir também a gritaria das crianças que de baixo zombavam dele, Guideon se prendeu do cabo e com isso deu um fim à própria vida, deixando seu pai enlutado, desconsolado e humilhado para sempre.

Na contramão das gerações literárias descritas até aqui, chegamos à década de 1990, época em que a literatura hebraica viveu uma nova fase. Dentre os escritores da nova geração, chamada de "geração Pós Pós", encontra-se o escritor contemporâneo Etgar Kéret nascido em 1967, e que pertence ao grupo de escritores pós-modernistas e pós-sionistas, cuja literatura transcorre num presente prolongado. Nos seus contos é possível perceber que as narrativas curtas acontecem como se fossem histórias em quadrinhos, ou pequenos relatos inspirados em telas de TV, ou clipes que seguem uma espécie de roteiro cinematográfico. ${ }^{9}$ Alguns de seus contos exploram justamente o conflito intergeracional quebrando, no entanto, os paradigmas conhecidos na literatura hebraica até então. Nas narrativas de Kéret os papeis se invertem, pais e filhos não se comportam exatamente como deles se espera que se comportassem socialmente. Um texto exemplar neste sentido é o conto Lishbor et hahazir (Quebrar o porco), publicado em 1994 e que faz parte do livro Gaaguai le Kissinger (Saudades de Kissinger). Neste conto o pai se comporta como uma criança, ele incentiva seu filho Yoav a quebrar um cofre cheio de moedas segurando um martelo na mão. Yoav por outro lado, apegou-se ao porquinho que, adquirindo características humanas, ganhou dele o nome de Pessachzon. Yoav se afeiçoou ao porquinho-cofre, que em suas mãos faz travessuras, mas o pai insiste para que ao ficar cheio de moedas, fosse finalizada sua missão no mundo, ou seja, que ele fosse quebrado para que com as moedas ali acumuladas o filho adquirisse um bem, um objeto. A respeito deste conto Rozenchan afirma:

Kéret escreve por vezes do ponto de vista de uma criança, e usa essa técnica para apontar a hipocrisia do comportamento adulto. Em Quebrar o Porco, por exemplo, o menino ganha um porquinho-cofre do pai para nele guardar as moedas que ganhará se tomar diariamente o seu achocolatado. O menino queria na realidade um boneco emblemático de desenho animado. Acontece que ele se apaixona pelo porquinho e valoriza exatamente o oposto do que o pai quer que aprenda. Seu porquinho-cofre se torna o seu maior tesouro, não pelas moedas acumuladas, mas pelos laços de amizade criados. ${ }^{10}$

\footnotetext{
${ }^{7}$ OZ, 1978, p. 34 .

${ }^{8}$ OZ, 1978, p. 36.

${ }^{9}$ ROZENCHAN, 2008, p. 136.

${ }^{10}$ ROZENCHAN, 2008, p. 141.
} 
Já a sexta antologia de narrativas curtas chamada Takalá Biktzê hagalaksia (Um incidente nos confins da galáxia), rendeu ao escritor Etgar Kéret o prêmio Sapir em 2018, no mesmo ano de sua publicação. Como é marca de sua escrita, as narrativas de Kéret se dirigem ao leitor numa linguagem coloquial e informal. Sua escrita por vezes bem humorada tem como personagens pessoas comuns, que em determinadas situações demonstram um comportamento inesperado e até estranho. Humor, depressão, brigas, conflitos entre casais, o absurdo, a ironia e a subversão são temas pelos quais suas narrativas transitam com extrema facilidade. Um dos temas condutores de alguns de seus contos é precisamente o conflito entre filhos e pais na contemporaneidade, onde por vezes os pais têm um comportamento tão infantil e surreal, mostrando como os papeis dos atores sociais na era pós-moderna se invertem, e os filhos levam os pais a agirem como se eles próprios fossem crianças. Em sua narrativa nada está definido de antemão, tudo parece ser imprevisível. A seguir é feita uma referência a três contos que têm justamente o tema do conflito entre gerações como momento central, e os três contos estão nesta mesma antologia.

No conto Al taassê et zêe (Não faça isso), Kéret coloca o leitor diante de um homem prestes a se jogar do topo de um prédio. O garoto personagem do conto, que se chama Pit Pit, descobre esse homem antes mesmo que seu pai. E antes que o pai percebesse que do alto de um prédio de quatro andares havia um homem prestes a pular para baixo, Pit Pit declara que o tal homem está se preparando para voar. Enquanto o pai tenta evitar que o homem acabe com sua vida e grita de baixo para que o mesmo se detenha, Pit Pit, o filho, que segura o pai pela cintura grita e incentiva o homem a pular imaginando ser ele um super-herói e ainda lhe pergunta: "Você tem forças sobrenaturais?". ${ }^{11}$ Quando o homem lá do alto grita que ele não pode mais e que está sem forças pois fora abandonado por uma mulher ou pela esposa, assim conclui o pai, Pit Pit, um pequeno menino da pós-modernidade que não obedece seu pai e tem personalidade e luz própria, contraria o nervosismo do pai que tenta acalmar o homem impedindo-o de se matar, e insiste gritando para o alto: "E daí, voe já de uma vez". ${ }^{12}$

O pai grita para o homem que a vida apronta muito com as pessoas mas que é preciso superar as dificuldades e prosseguir vivendo, quando então ele se vale do menino para tentar persuadir o homem a se deter e diz: "Há aqui um menino, ele aponta para Pit Pit, ele não precisa ver isto", ao que o garoto retruca e diz: "Eu sim, eu sim! E voe já de uma vez antes que escureça". ${ }^{13} \mathrm{O}$ pai segura o garoto no colo e sobe correndo até o topo do prédio. Mas ao chegar ao alto o homem já não se encontrava mais ali, ele realmente já tinha se espatifado no chão. $\mathrm{O}$ pai ficou aturdido, ele fora incapaz de salvar a vida de um homem, quando então Pit Pit começou a recriminá-lo e lhe disse: "Ele voou, ele voou e por tua causa não conseguimos ver nada, por tua causa". ${ }^{14}$

No segundo conto da mesma antologia, Machar Kupá (Amanhã, Uma Caixa Registradora), os papéis de pai e filho novamente são invertidos por Kéret. Neste conto é um menino que leva seu pai, um homem divorciado e amargurado, a cometer loucuras com o intuito de ser contentado com um estranho pedido. Assim, no dia do aniversário, o pai leva Lidor, seu garoto, para o shopping após ter lhe dado um drone de presente que trouxera do exterior. Pai e filho foram ao shopping para comprar as baterias do drone. E naquele lugar abarrotado de gente, Lidor teima em subir na escada rolante que desce e o pai, obviamente, vai atrás causando tumulto no centro de compras, argumentando para si mesmo que o garoto é "um menino adorável". Ao chegar na loja de doces no terceiro andar, o pai diz ao garoto: "Escolhe o que

\footnotetext{
${ }^{11}$ KÉRET, 2018, p. 11.

12 KÉRET, 2018, p. 11.

${ }^{13}$ KÉRET, 2018, p. 12.

${ }^{14}$ KÉRET, 2018, p. 13.
} 
você quiser, não importa o preço e papai vai comprar para você"'. ${ }^{15}$ Após percorrer a loja, o menino decide que quer a caixa registradora de presente. Quando o pai lhe diz que ela não estaria à venda o menino insiste: "Eu quero a caixa registradora, você prometeu... você é um mentiroso. Lidor grita e chuta minha perna com toda a força". ${ }^{16}$ Diante da recriminação do filho o pai se transforma. Ele decide oferecer ao vendedor mil shekalim que logo se transformarão em 2 mil, mas o vendedor se recusa a negociar, ao fim de contas, a caixa registradora não estava à venda.

Nesse momento, receber ou conseguir a caixa registradora torna-se um imperativo que o pai deve conseguir, ao final de contas ele não pode decepcionar um menino da idade de Lidor. O pai insiste e chega ao absurdo de tentar pegar a caixa registradora à força e pela qual ele tenta colocar as notas no bolso do vendedor, olha para o garoto e diz a si mesmo todo orgulhoso: "Lidor me olha como se eu fosse um rei. Não há nada mais agradável do que ver seu filho olhando para você desta forma". ${ }^{17}$ Quando o pai conseguiu remover a máquina do lugar, o vendedor retornou ao estabelecimento acompanhado do segurança do shopping ameaçando chamar a polícia. A narrativa quase acabou mal por causa da infantilidade do pai. O pai que teme ter de enfrentar o filho e com isso se indispor com ele, prefere assumir um comportamento infantil e até irresponsável com o intuito de atender ao desejo de seu pequeno, que igual a muitas crianças da geração pós-moderna não pode ser contrariado, pois ao final de contas ele é um doce garoto.

Já no conto Ugat Peirurim (Um bolo de migalhas), uma mãe de idade avançada, leva o filho para um almoço a fim de celebrar seus cinquenta anos. No restaurante e perante Charlie, um atendente gordo e entediado, mãe e filho discutem pois o aniversariante que completara cinco décadas de vida deseja comemorar seu dia comendo panquecas. Nas palavras do filho de cinquenta anos podemos constatar: "Eu quero pedir uma torre de panquecas com xarope e chantili, porém mamãe pede, como de costume, que eu peça algo mais saudável. É meu aniversário, meu aniversário de cinquenta anos. Deixa mãe eu pedir as panquecas, somente desta vez". ${ }^{18}$ No final, a mãe que não se incomoda com o vexame público, decide premiar seu filho tanto com as panquecas como com um bolo de migalhas que ela lhe preparou em casa. Ao retornar para casa, a mãe compra para o filho após ele insistir como presente de aniversário um bilhete de loteria, porém o adverte que sua chance de ganhar seria ínfima. No dia do sorteio pela TV, o filho de meia idade que é tratado pela mãe como se fosse uma criança pequena, enquanto a mãe entediada com o programa do sorteio foi até o banheiro, viu a seguinte cena sendo transmitida e sobre a mesma ele reflete da seguinte forma:

Sobre a primeira bola que saiu da máquina apareceu o número 46 que é o número da nossa casa. Na segunda bola estava o número 30 , que é a idade que mamãe tinha quando meu pai morreu e eu nasci. Na terceira bola apareceu o número 33 que é o número de comprimidos que mamãe tomava antes que lhe receitassem o remédio para o glaucoma. Que estranho que todos os números que aquela loira escolheu tinham relação com a vida da minha mãe e comigo. Os últimos três números eu sequer olhei... pois seria muito triste se mamãe e eu tivéssemos que passar a viver em casas separadas. ${ }^{19}$

O mesmo filho de meia idade que provavelmente tinha em mãos o bilhete premiado e com ele poderia dar um novo rumo à sua vida, está tão infantilizado e ligado ao cotidiano criado pela

\footnotetext{
${ }^{15}$ KÉRET, 2018, p. 49.

${ }^{16}$ KÉRET, 2018, p. 50.

${ }^{17}$ KÉRET, 2018, p. 50.

${ }^{18}$ KÉRET, 2018, p. 63.

${ }^{19}$ KÉRET, 2018, p. 69.
} 
mãe que ele nem deseja continuar vendo os números da sorte. Ele bem mais deseja continuar levando essa mesma vida que aos olhos dos outros poderia ser constrangedora e até ridícula, mas que a seus próprios olhos parecia perfeita.

Dessa forma, se na literatura da Geração da Terra não havia conflitos entre pais e filhos e predominava um temor reverencial dos jovens perante a figura dos pioneiros e dos pais fundadores da nação, e na literatura da Geração do Estado os conflitos entre gerações aparecem e são tema dominante dessa vertente literária, as narrativas de Kéret subvertem a relação entre pais e filhos, mostrando por vezes realidades que beiram o grotesco ou o absurdo, conduzindo o leitor a refletir sobre situações do cotidiano e sobre as novas realidades e facetas da literatura pós-modernista em Israel.

\section{Referências}

KÉRET, Etgar. Lishbor et hahazir (Quebrar o porco). Gaaguai leKissinger (Saudades de Kissinger). Tel Aviv, Zmora Bitan, 1994. Takalá biktzê hagalaksia (Um incidente nos confins da Galáxia). Hevel Modi'in, Kineret, Zmora Bitan, Dvir, 2018. OZ, Amós. O Caminho do Vento. O Novo Conto Israelense. São Paulo, Símbolo, 1978. . De Amor e Trevas. São Paulo, Companhia das Letras, 2005.

ROZENCHAN, Nancy. Subversão e humor na obra de Etgar Kéret. Cadernos de Língua e Literatura Hebraica, ${ }^{\circ}$ 6. São Paulo, Targumim, 2008.

SCHWARTZ, Igal. Caminhos da Prosa. Literatura de Israel nº 2. São Paulo, 1998.

YEOSHUA, A.B. O Silêncio Contínuo de um Poeta. O Novo Conto Israelense. São Paulo, Símbolo, 1978. 